This item was submitted to Loughborough's Research Repository by the author.

Items in Figshare are protected by copyright, with all rights reserved, unless otherwise indicated.

\title{
An investigation into whether building information modelling (BIM) can assist with construction delay claims
}

PLEASE CITE THE PUBLISHED VERSION

PUBLISHER

BIM Academy

VERSION

AM (Accepted Manuscript)

LICENCE

CC BY-NC-ND 4.0

\section{REPOSITORY RECORD}

Gibbs, David-John, Stephen Emmitt, Kirti Ruikar, and Wayne E. Lord. 2019. "An Investigation into Whether Building Information Modelling (BIM) Can Assist with Construction Delay Claims". figshare. https://hdl.handle.net/2134/11391. 
This item was submitted to Loughborough's Institutional Repository (https://dspace.lboro.ac.uk/) by the author and is made available under the following Creative Commons Licence conditions.

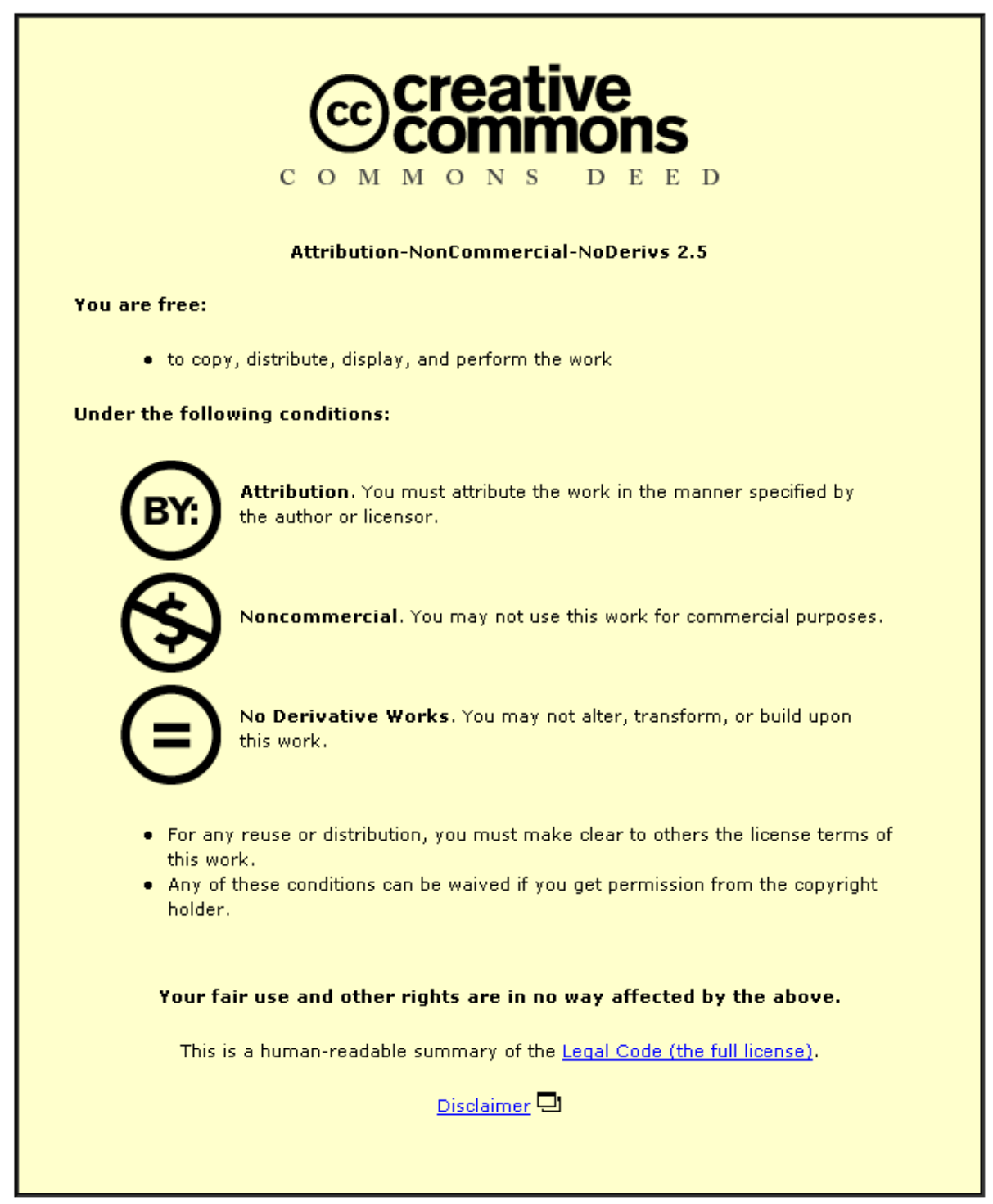

For the full text of this licence, please go to: http://creativecommons.org/licenses/by-nc-nd/2.5/ 


\title{
AN INVESTIGATION INTO WHETHER BUILDING INFORMATION MODELLING (BIM) CAN ASSIST WITH CONSTRUCTION DELAY CLAIMS
}

\author{
David-John Gibbs ${ }^{1}$, Stephen Emmitt ${ }^{2}$, Kirti Ruikar², Wayne Lord ${ }^{2}$ \\ ${ }^{1}$ DAQS Ltd, Stokes Suite, Unit 7A, East Bridgford Business Park, Kneeton Road, East Bridgford, \\ Nottingham, NG13 8PJ, UK \\ ${ }^{2}$ School of Civil and Building Engineering, Loughborough University, Loughborough, Leicestershire, \\ LE11 3TU, UK
}

\begin{abstract}
It is probable that a construction project anywhere in the world will encounter some form of delay as a consequence of change. The impact of the delay on a project will vary, but it is likely to have a negative financial outcome. Compensation can be requested by an affected party in the form of a claim; however, issues of liability and quantum can be difficult given the ever increasing complexity of construction work involving numerous differing successive parallel tasks with varying levels of interrelated resources. Experts are often employed to analyse delays based on project records and report their findings to a tribunal. This paper identifies the difficulties associated with the retrieval and representation of information for delay claims and recognises technological opportunities to deal with these challenges. The potential to exploit aspects of BIM to support these possibilities are discussed, concluding that it can assist through the ease of access to coordinated contemporaneous project information and the use of visualisation through multiple dimensions. In order to support this initiative a detailed review of the literature is undertaken which forms part of an Engineering Doctorate.
\end{abstract}

Keywords: BIM, claims, construction, delay, disputes, visualisation.

\section{INTRODUCTION}

The construction lifecycle is a complex endeavour which incorporates multiple parties to undertake numerous tasks each with varying levels of interrelated resources. The risks associated with construction projects are high and are not supported by the small profit margins that exist. If nothing was to change on a project it would be completed to the planned cost, quality and time; however, even the best laid plans will deviate. Reports show that a trade-off between these elements is likely, with over a third of projects not being completed to the planned time and cost (Egan, 1998). Organisations cannot financially absorb this difference; therefore, the affected party can claim compensation. In order for a claim to be made for time delays, a delay analysis must be undertaken.

Currently, no research has been undertaken to investigate whether elements of BIM can be exploited to support construction delay claims. To bridge this gap, this paper explores both construction delay and BIM literature. The fundamentals of delay analysis are explained and some of the challenges encountered by analysts are discussed. Potential technological opportunities to mitigate these challenges are identified, and a connection to some of the benefits related to BIM are realised and discussed.

\section{DELAY}

The term delay is exhaustively used in the construction industry; however, no standard form of construction contract defines the term due to the comparative nature in which it is used (Pickavance, 2010). For the purpose of this paper, delays are referred to as an unanticipated 
extension to the overall planned time period and/or the incident which prolongs the duration of an activity without affecting the overall project duration (Bramble, 2000). Therefore, the process of analysing delays can be viewed as the forensic investigation into an issue which has caused a time overrun (Farrow, 2001). This is distinctly different from disruption, a term generally conjoined with delay, which is the loss of efficiency due to low productivity or an interference with progress (Cooke, 2009). The topic of disruption is not considered in this paper; however, both delay and disruption can result in a claim and some of the discussion may be transferable.

\section{Categories of delay}

Subject to the claiming party, different forms of compensation can be requested depending on how the delay is classified. In order to analyse delay, the first step is to decipher responsibility by categorising whether the event is excusable or non-excusable.

Non-excusable delays, also known as culpable delays, contractor delays or inexcusable delays (SCL, 2002), are delays within the contractors control; thus, they assume responsibility for the delay and its impact on the other parties (Bramble, 2000). In contrast, excusable delays, also known as non-culpable delays and employer delays (Cooke, 2009), are delays beyond the control of the contractor which allows them a form of compensation. The compensation available will depend on whether the event is deemed compensable or non-compensable.

Under a non-compensable event the contractor can obtain an extension of time which provides the contractor with an extension to the agreed contract completion date and acts as a mechanism to protect the client's entitlement to liquidated damages. If the delay event is deemed compensable the contractor can claim loss and expense, but they must prove the damages they have suffered from events not their fault. A combination of both forms of compensation is also possible.

The client can claim compensation in the form of actual damages or liquidated damages. Actual damages are calculated post delay and must be proven, whereas liquidated damages are included in the contract as a pre-estimate of the damages the client will suffer if the project is not completed by the contract date. The contractor is legally obliged to pay the value set in the contract unless they claim excusable delay.

The exact conditions for determining the category of delay will be outlined in the construction contract. However, it is unlikely that there will be a single form of delay on the project which adds to the complexity of categorisation and allocation of responsibility. More probable than not, a construction project will encounter multiple delays which may occur at the same time and/or become intertwined with each other. The challenge given to delay analysts is to categorise and quantify these delays and represent the findings in a suitable manner.

\section{Delay analysis - the current position}

In order to claim compensation for delay, the burden of proof is placed with the claimant. If enough evidence is provided in their favour, the burden of proof passes over to the other party (Haidar, 2011).

Unlike criminal proceedings, the standard of proof in civil proceedings is based on an event being more likely than not to have occurred. The 'balance of probabilities' principle states that, no matter how small an amount, one side's claim must prove to be more likely than the other to be successful. The balance can be tipped on the strength of evidence; however, the quantity and quality available will vary between claims and the standard required to shift the balance will depend on the severity of the case. In general, the stronger the evidence the more likely the claim is to be successful, with particular weighting given to contemporaneous records. Records can take numerous forms and include computer-aided project management tools (Haidar, 2011).

\footnotetext{
11.gibbs@lboro.ac.uk
} 
Scheduling project management tools are an accepted method to illustrate delay claims as long as they prove reliable (Barry, 2009). The project schedule, which is different from project planning, generates an overall project duration by sequencing all of the activities required to complete the works using mathematical calculations and logic (CIOB, 2011). A critical path can be shown on the schedule which depicts the key activities required to finish the project with the shortest duration. If there is a time slippage on any of these critical activities, the project duration will be extended. The activities not on the critical path can contain float, which is the duration they can be delayed before becoming critical to the overall project duration. If undertaken correctly, the schedule will show how change impacts the project duration.

There are a variety of delay analysis methodologies available which use schedules, with different titles given to the same methodologies. Bubshait (1998) states that there is no universal method for analysing delay; therefore, the selected methodology should be the one which best represents the claim. The SCL Delay and Disruption Protocol (2002) recommends the following methodologies for analysing delay: 1. As-planned vs as-built; 2. Impacted asplanned; 3. Collapsed as-built; or 4. Time impact analysis. Arditi (2006) comments on the usefulness of each of these concluding that time impact analysis is the most reliable. Despite this, the choice of methodology can be influenced by a variety of factors, most notably, the availability of records (Braimah, 2008).

\section{Delay claim challenges}

\section{Retrieval of information}

Records are fundamental in analysing and supporting delay claims; however, retrieving the information, if at all it exists, is not always straightforward. Research by the CIOB (2008) showed that $22 \%$ of respondents were not aware of delay and compensation related events being recorded. Pickavance (2010) attributes this to the fact that there is no requirement in many standard forms of construction contract to keep records.

Where records are kept throughout the lifecycle of a project they will take a range of forms for a variety of purposes. Consequently, mass amounts of information is stored and communicated on a project (Vidogah, 1998). The most useful records, with respect to delay claims, are progress records and change management records (Pickavance, 2010). It is probable that this information would have been recorded in some form; however, it may not be easily retrieved (Scott, 1990). Accessing documents, particularly paper based items, proves a difficult challenge and can be a costly and laborious process (Vidogah, 1998). Research by Joia (1998) found that consultancy firms spent 8 hours a week retrieving lost or incorrectly stored data. The PIX Protocol (Goodwin, 2004) attributes this to the inherent use of paper on construction projects despite the advanced IT systems most organisations possess.

\section{Visualisation}

A delay claim will attempt to demonstrate the claimants interpretation of what occurred on the project. A report will identify the cause and effect relationship of the damages suffered from the other party's actions (Trauner, 2009). The quality of the report is likely to influence the success of the claim (Liulihong, 2011) and must prove liability, causation and quantum (Williams, 2003).

At present, a delay claim may involve numerous lever arch files containing complex schedules and supporting evidence. Although the various delay analysis methodologies are accepted as a means to show the cause and impact of delay, they can be difficult to understand (Kumaraswany, 2003). Deciphering the information to allow for an informed judgment to be made can prove a challenging task for the tribunal who may have limited construction and schedule knowledge. These points are emphasised by Arden L.J. in the Hunte v Bottomley case: 
"Many cases of this kind, however, and I am sorry to say that this is one of them, are prepared in a way which makes it very difficult for members of this court when reading the papers in preparation for the appeal hearing, to read the plan, map, diagram or photograph correctly, or to follow fully the submissions of the parties about those documents or the court cannot be certain about what the plan, diagram, map or photograph shows until the appeal is opened and they are fully explained. Those who prepare bundles or skeleton arguments would do well to remember that a plan, map, diagram or photograph which is clear to people who are fully familiar with the case may well not be wholly clear to a judge coming to the case for the first time."

To combat these problems, the courts are moving closer to e-disclosure and the use of screens as a method of communicating a case. Therefore, the potential to use modern technology to represent delay as a response to change is possible.

\section{TECHNOLOGICAL OPPORTUNITIES}

Compared to the phases in the lifecycle of a construction project, construction claims have benefited the least from bespoke developments in information technology. Instead, they work off systems built for other purposes which can limit the output desired from the software (Vidogah, 1998).

\section{Retrieval}

It is widely stated in the literature, and accepted in the industry, that a central, electronic, hub should be used to store all project information. Such a document management system can house contemporary records which can be used to monitor and control the project.

A reason why disputes occur is due to a difference of information (Pickavance, 2010). A centralised, electronic, hub ensures that the most up to date information is readily accessible to all parties involved on the project. In the event of a delay claim, all of the project information can be understood, accessed, sorted, filtered and reported at a faster rate than paper or unmanaged electronic information (CIOB, 2011). A variety of organisations, external to the construction project, offer these services using web-based platforms (Chassiakos, 2008). If these systems are implemented and followed correctly the claim is less likely to be disputed (Vidogah, 1998). Needless to say, the system used is only as good as the information put in and an adequate record keeping system must be adhered to (CIOB, 2011).

If the information is readily available to undertake a delay analysis and act as supporting evidence, technological developments can further assist with visualising the claim.

\section{Visualisation}

Pickavance (2010) identifies that there are three different ways in which delay evidence can be presented: 1. Orally; 2. By hand documentation; 3. By computerised presentation of electronic data. Extending the use of computerised presentation past construction schedules, the potential to use computer generated visualisations to assist with the communication of delay claims are discussed.

The use of visualisations to improve communication is predominantly used in architectural design but its benefits can be realised throughout the project lifecycle (Bouchlaghem, 2005). Its opportunity to assist with legal proceedings is expected to rise given that courts are becoming increasingly technologically sophisticated (Narayanan, 2001) and, if used correctly, they may be suitable in adjudication and some arbitrations (Pickavance, 2010). Pickavance (2007) acknowledges the possibility of using forensic animations to resolve disruption claims but recognises that their value as evidence will vary depending on how they are used and the supporting information behind their generation (Schofield, 2005).

${ }^{1}$ d.gibbs@lboro.ac.uk 
Outside of the construction industry, visualisations have been used in the courtroom. These include the 1998 UK inquiry into the events of Bloody Sunday in Londonderry 1972 and the 2001 Carla Terry murder case in Connecticut. The latter identifies the following requirements for visualisations to be accepted as supporting evidence in the US courts.

- The equipment used is standard in the field and is shown to be in good working order

- Qualified operators, procedures and reliable software are employed to produce the output

- The equipment was operated correctly

- The exhibit is identified as the output produced

An array of software providers offer services in which models can be designed in 3D; however, this cannot be directly linked to the delay analysis information available, thus, the standalone model may be insufficient. A solution to combine the two elements together is found in BIM.

\section{A SOLUTION - BIM?}

BIM is not a new idea (Napier, 2009), but has recently gained widespread interest as a result of the UK governments' mandate to use it on public sector projects by 2016 (Cabinet Office, 2011). Despite the increase in awareness, research by the National Building Specification (NBS, 2012) discovered that $21 \%$ of respondents were uncertain as to what BIM was despite being defined in their 2011 report as "a rich information model, consisting of potentially multiple data sources, elements of which can be shared across all stakeholders and be maintained across the life of a building from inception to recycling (cradle to cradle). The information model can include contract and specification properties, personnel, programming, quantities, cost, spaces and geometry” (NBS, 2011).

The potential opportunities and challenges associated with BIM are widely discussed in the literature and can be realised in all aspects of the construction lifecycle (Eastman, 2011). If used correctly, it is suggested that fewer projects will result in disputes due to improved collaboration. This may be true as little documentation on BIM related disputes exists, although it could be argued that this is attributed to the limited number of BIM projects undertaken.

From identifying the technological opportunities available to enhance delay analysis, opportunities are recognised in BIM for both projects which used it through its lifecycle, and for those which have not used it at all.

\section{Coordinated contemporaneous project information}

BIM offers a way of coordinating all project information throughout its lifecycle. If a project used BIM from inception and followed recommended record keeping procedures, all project information would be stored in a central database and linked to a 3D model. Through the potential of mobile computing on construction projects, the recording of high value contemporaneous records may increase.

Furthermore, the disparate information which traditionally exists on construction projects is removed as all information can be coordinated. This is supported by developments from buildingSMART to assist interoperability of software through Industry Foundation Classes (IFC). With a common language between software packages, information can easily be updated and the impact of change realised through the linked information. The representation of this information can be further enhanced through the visual capabilities of BIM. 


\section{Visualisation through multiple dimensions}

BIM moves away from traditional 2D design and represents the project in 3D using objects which respond to each other's properties and recognise space. Through the collaborative working processes and interoperable nature of information exchange, multiple dimensions (nD) open up as a result of the coordinated information (Tao-Chiu, 2005).

With respect to delay claims, the fourth dimension (time) and fifth dimension (cost) appear to offer assistance; however, they are currently only considered as support for project control (Hartmann, 2012). Current project scheduling software links time and cost but it is not always easy to understand the cause and effect of change. The innovation is to use the multiple dimensions by linking the information generated in the delay analysis to an $\mathrm{nD}$ representation of the project. This information can then be passed to the tribunal to support the delay claim subject to legal requirements.

In an event where BIM, or 3D modelling, were not used on a project, and it may prove too time consuming to model the project, laser scanning could be used to quickly produce a 3D model using point clouds (Tang, 2010). The information produced by the delay analyst could then be linked to a visual representation of the project to better represent the cause and effect of the delay.

\section{CONCLUSIONS}

The paper presents a review of the literature to show the current position of delay claims. It recognises two challenges that delay analysts encounter as the retrieval of information and the clear representation of the analysis. Technological opportunities in the form of document management systems and computerised visualisations are identified as ways to combat these challenges. BIM is recognised as a platform which can support these attributes in one system through coordinated project information and $\mathrm{nD}$ modelling. Its use can be extended to projects not using 3D modelling through the advancements of laser scanning.

In order to progress this initiative, the legal aspects of BIM need to be explored. Issues on ownership and intellectual property are not clear due to the lack of rules and protocols set out. The ability to use the information in the model as evidence needs to be investigated in relation to e-disclosure. If feasible, or whether paper documents must be presented, a clear progression in research is to undertake a case study to determine the opportunities and challenges of exploiting aspects of BIM to assist with construction delay claims. This will continue to be addressed through Engineering Doctorate research. 


\section{REFERENCES}

Arditi, D., \& Pattanakitchamroon, T. (2006). Selecting a delay analysis method in resolving construction claims. International Journal of Project Management, 24, 145-155.

Barry, D. (2009). Beware of the dark arts! Delay analysis and the problems with reliance on technology. Society of Construction Law.

Bouchlaghem, D., Shang, H., Whyte, J., \& Ganah, A. (2005). Visualisation in architecture, engineering and construction (AEC). Automation in Construction, 14, 287-295.

Braimah, N., \& Ndekugri, I. (2008). Factors influencing the selection of delay analysis methodologies. International Journal of Project Management, 26, 789-799.

Bramble, B., \& Callahan, M. (2000). Construction delay claims $3^{\text {rd }}$ ed. Gaithersburg: Aspen Law and Business.

Bubshait, A., \& Cunningham, M. (1998). Comparison of Delay Analysis Methodologies. Journal of Construction Engineering and Management, 315-322.

Cabinet Office., 2011. Government Construction Strategy. May 2011.

Chassiakos, A., \& Sakellaropoulos, S. (2008). A web-based system for managing construction information. Advances in Engineering Software, 39, 865-876.

CIOB. (2008). Managing the Risk of Delayed Completion in the $21^{\text {st }}$ Century. The Chartered Institute of Building.

CIOB. (2011). Guide to Good Practice in the Management of Time in Complex Projects. Wiley-Blackwell.

Cooke, B., \& Williams, P. (2009). Construction Planning, Programming and Control $3^{\text {rd }}$ ed. West Sussex, England: Wiley-Blackwell.

Egan, J. (1998). Rethinking Construction: report of the construction task force on the scope for improving the quality and the efficiency of UK construction. Department of the Environment, Transport and Regions.

Eastman, C., Teicholz, P., Sacks, R., \& Liston, K. (2011). BIM Handbook: A guide to Building Information Modeling for Owners, Managers, Designers, Engineers, and Contractors. Hoboken, New Jersey: John Wiley \& Sons, Inc.

Farrow, T. (2001). Delay Analysis - Methodology and Mythology. Society of Construction Law.

Goodwin, P. (2004). The PIX Protocol: A Risk Reduction Tool for Construction Projects. Society of Construction Law, May 2004.

Haidar, A., \& Barnes, P. (2011). Delay and Disruption Claims in Construction: A practical approach. London, England: ICE publishing.

Hartmann, T., Meerveld, H., Vossebeld, N., \& Adriaanse, A. (2012). Aligning building information model tools and construction management methods. Automation in Construction. ARTICLE IN PRESS.

Joia, L. (1998). Large-scale Reengineering in Project Documentation and Workflow at Engineering Consultancy Companies. International Journal of Information Management, 18(3), 215-224.

Kumaraswamy, M., \& Yogeswaran, K. (2003). Substantiation and assessment of claims for extensions of time. International Journal of Project Management, 21, 27-38.

Liulihong. (2011). Study on the Present Condition of Construction Claim and Countermeasure. Energy Procedia, 13, 2837-2841.

Napier, B., Connolly, K., \& Jernigan, F. (2009). Building Information Modeling - A report on the current state of BIM technologies and recommendations for implementation. The State of Wisconsin Department of Administration Division of State Facilities.

Narayanan, A., \& Hibbin, S. (2001). Can animations be safely used in court? Artificial Intelligence and Law, 9, 271-293.

NBS. (2011). Building Information Modelling.

NBS. (2012). National BIM Report. Report

Pickavance, K. (2007). Using advanced forensic animations to resolve complex disruption claims. Society of Construction Law.

11.gibbs@lboro.ac.uk 
Pickavance, K. (2010). Delay and Disruption in Construction Contracts $4^{\text {th }}$ ed. London, England: Sweet \& Maxwell.

Schofield, D., Hussin, N., \& Shalaby, M. (2005). A Methodology for the Evidential Analysis of Computer-Generated Animation (CGA). Proceedings of the Ninth International Conference on Information Visualisation (IV'05).

SCL. (2002). Delay and Disruption Protocol. Society of Construction Law.

Scott, S. (1990). Keeping better site records. Project Management, 8(4), 243-249.

Tang, P., Huber, D., Akinci, B., Lipman, R., \& Lytle, A. (2010). Automatic reconstruction of as-built building information models from laser-scanned point clouds: A review of related techniques. Automation in Construction, 19, 829-843.

Tao-Chiu, K., Kam-Din, A., \& Kwan-Wah, F. (2005). The utilisation of building information modelling in nD modelling: a study of data interfacing and adoption barriers, ITcon, 10.

Trauner, T., Manginelli, W., Lowe, J., Nagata, M., \& Furniss, B. (2009). Construction Delays: Understanding the clearly, analysing them correctly $2^{\text {nd }}$ ed. London, England: Elsevier.

Vidogah, W., \& Ndekugri, I. (1998). A review of the role of information technology in construction claims management. Computers in Industry, 35, 77-85.

Williams, T., Ackermann, F., \& Eden, C. (2003). Structuring a delay and disruption claim: An application of cause-mapping and system dynamics. European Journal of Operational Research, 148 192-204.

${ }^{1}$ d.gibbs@lboro.ac.uk 